\title{
IDENTIFICACIÓN MORFOLÓGICA Y MOLECULAR DE Meloidogyne javanica EN UNA PLANTACIÓN DE PAPAYA (Carica papaya L.) EN POCOCÍ, LIMÓN, COSTA RICA
}

\author{
Walter Peraza-Padilla
}

\begin{abstract}
Palabras clave: Nematodo agallador; patrones perineales; análisis molecular.
Keywords: Root-know nematode; perineal patterns; molecular analysis.
\end{abstract}

Recibido: 14/07/2020

Aceptado: 11/12/2020

RESUMEN

Introducción. Meloidogyne es un género de nematodos fitoparásitos de importancia agrícola mundial. La diagnosis correcta de estas debe incluir el uso de diferentes herramientas de identificación, ya que representa muchas especies. Objetivo. Identificar morfológica y molecularmente una población de Meloidogyne asociada a una parcela de papaya (Carica papa$y a$ L.) en Costa Rica. Materiales y métodos. En abril de 2015, en el cantón de Pococí-Limón, se detectaron agallas en el sistema radical de una plantación de papaya. Se recolectaron raíces agalladas y se extrajeron hembras, masas de huevos y juveniles $\left(\mathrm{J}_{2}\right)$ de Meloidogyne sp. Se examinaron patrones perineales de hembras, así como su taxonomía. Los estadios juveniles se identificaron morfológica y molecularmente mediante PCR-RFLP. Se amplificó una región intergénica del genoma mitocondrial (COII/16S) con los imprimadores $\mathrm{C} 2 \mathrm{~F} 3$ y 1108 y se generaron productos de PCR de $1,7 \mathrm{~kb}$. Resultados. Al tratar los productos de PCR con endonucleasas,

\section{ABSTRACT}

Morphological and molecular identification of Meloidogyne javanica in a papaya orchard (Carica papaya L.) in Pococi, Limon, Costa Rica. Introduction. Meloidogyne is a genus of phytoparasitic nematodes of agricultural importance worldwide. The correct diagnosis must include the use of different identification tools, since it represents many species. Objective. To morphologically and molecularly identify a Meloidogyne population associated with a papaya (Carica papaya L.) plot in Costa Rica. Materials and methods. In April 2015, in Pococi-Limon, galls were detected in the radical system of a papaya plantation. Plant material with root galls were collected, and females, egg masses and juveniles $\left(\mathrm{J}_{2}\right)$ of Meloidogyne sp. were extracted. Perineal patterns of females were examined as well as their taxonomy. Juvenile stages were morphologically and molecularly identified by RFLP-PCR. An intergenic region of the mitochondrial genome $(\mathrm{COII} / 16 \mathrm{~S})$ was amplified with primers $\mathrm{C}_{2} \mathrm{~F}_{3}$ and

1 Universidad Nacional, Laboratorio de Nematología, Escuela de Ciencias Agrarias. Heredia, Costa Rica. Correo electrónico: walter.peraza.padilla@una.ac.cr (D) 0000-0003-4651-5555. 
se produjeron tres fragmentos, uno de 1000, 460 y $250 \mathrm{pb}$ con la enzima AluI, cinco fragmentos, uno de 660, 600, 150, 105 y 85 pb con la enzima DraI y no hubo corte del producto PCR con la enzima Hinf I, es decir, fue de 1,7 pb. Por medio de las técnicas se logró la caracterización de Meloidogyne javanica asociada al sistema radical del cultivo. Conclusión. La correcta identificación de una especie de nematodo es primordial para evitar su propagación a otros sitios donde aún no está presente y es un aspecto relevante para conocer cuáles de esas especies están asociadas a un determinado cultivo, para definir estrategias de combate.

\section{INTRODUCCIÓN}

La papaya (Carica papaya L.) es la tercera fruta tropical más producida y consumida en el mundo después del mango y la piña. Es originaria de Centroamérica y el sur de México, donde ya era cultivada antes del descubrimiento de América. Este fruto, es uno de los más importantes desde el punto de vista económico y social, ya que es fuente de ingresos para miles de familias y se posiciona como una fuente de ingreso de divisas para muchos países gracias a su demanda internacional (Valencia et al. 2017).

Esta fruta se produce en más de 60 países principalmente tropicales y subtropicales en donde se propaga rápidamente, debido a la abundancia y viabilidad de sus semillas; además de los requerimientos de suelos fértiles y abundantes lluvias (De La Cruz et al. 2003). También, es reconocida por sus cualidades médico-gastrointestinales, así como insumo para la industria de los jugos (SAGARPA 2017).

Actualmente se cultivan alrededor de 440 000 ha en todo el mundo, con una producción de casi 12,5 millones de toneladas. La India y Brasil
1108 and $1.7 \mathrm{~kb}$ PCR products were generated. Results. PCR products subject to endonuclease digestion generated three fragments of 1000, 460 and $250 \mathrm{bp}$ with $A l u \mathrm{I}$, five fragments of 660, 600, 150, 105 and 85 bp with the DraI enzyme and there was no cut of the PCR product with the $\operatorname{Hinf} \mathrm{I}$ enzyme, it was $1.7 \mathrm{bp}$. The use of these techniques allowed the characterization of Meloidogyne javanica associated with the radical system of the crop. Conclusion. The correct identification of a nematode species is essential to prevent its spread to other sites where it is not yet present and it is a relevant aspect to know which of these species are associated with a certain crop, in order to define control strategies.

son los principales productores de papaya; sin embargo, también destacan países como México, Nigeria e Indonesia. El mercado internacional está dominado por México que exporta más de 130 000 toneladas al principal consumidor de papaya en el mundo que es Estados Unidos. Anualmente, la Unión Europea, el Reino Unido, Holanda y Alemania importan alrededor de 8000 toneladas anuales cada uno, mientras que España supera las 5000 toneladas anuales (Hueso et al. 2017).

En Costa Rica existen 3264 fincas dedicadas a la producción de papaya, las cuales representan un total 1393,5 ha. Las principales zonas productoras se encuentran en las provincias de Limón con 514,8 ha, seguido de Alajuela y Puntarenas respectivamente (INEC 2014). De acuerdo con la Promotora de Comercio Exterior (PROCOMER 2017), en 2016, la exportación de esta fruta alcanzó los \$3 millones y 3889 toneladas, donde Canadá es el principal país importador con un $52 \%$, seguido de España (14\%) y finalmente, Holanda (5\%).

La variabilidad de papayas en Costa Rica representa un potencial para el desarrollo de nuevas variedades o híbridos. Actualmente se 
produce la variedad Pococí, conocida como "papaya perfecta" que destaca por sus altos rendimientos, calidad de la fruta, uniformidad de las plantaciones, sabor y aroma. Este híbrido es protegido y desarrollado por el Instituto de Innovación y Transferencia de Tecnología Agropecuaria (INTA), adscrito al Ministerio de Agricultura y Ganadería, y la Universidad de Costa Rica (Bogantes et al. 2011).

El cultivo de papaya puede ver afectada su producción debido a la interacción de patógenos como hongos, bacterias, virus y nematodos. De estos últimos microorganismos, solo Meloidogyne spp. y Rotylenchulus spp. parecen tener importancia económica y se identifican mundialmente en ese cultivo (Inserra y Cartia 1976, Lamberti et al. 1980 y 1993, McSorley 1983 y 1992, Cohn y Duncan 1990, Luc et al. 2005). El daño que provocan las especies $M$. hapla, M. incognita y M. javanica en este cultivo, fue previamente reportada en Brasil (Chaful y De'Arc 1994).

En Colombia, Espinosa et al. (2004) y Jaraba et al. (2007), encontraron las especies $M$. arenaria, $M$. javanica y $M$. incognita, esta última, la especie más frecuente. Asimismo, en México, Cid del Prado et al. (2011) reportaron en los estados de Michoacán y Morelos a $M$. incognita raza 1 y $M$. arenaria en el estado de Morelos. En Pakistán, Khan et al. (2007, 2008) reportaron la presencia de $M$. incognita; y en Hawái Hine et al. (1965) identificaron la misma especie asociada a plantaciones de papaya. Además, Koenning et al. (1999), hallaron pérdidas del 15 al $20 \%$ en el rendimiento de esta fruta en Hawái causadas por Meloidogyne sp. y Rotylenchulus sp. Finalmente, en España Castillo y Gómez-Barcina (1993), indicaron la presencia de M. javanica en este cultivo.

Los géneros y especies mencionadas anteriormente afectan el sistema radical de la planta, donde ocasionan daños mecánicos y la formación de agallas (Chaful y De'Arc 1994). Cohn y Duncan (1990) mencionan que Meloidogyne spp. es capaz de ocasionar pudrición de la raíz lo cual disminuye la vida útil de las plantas de papaya, así como la reducción drástica de su productividad. Estos patógenos limitan el rendimiento y la producción de la fruta, pero en Costa Rica no existen datos sobre las pérdidas ocasionadas por nematodos en este cultivo.

Estudios realizados por Ramakrishnan y Rajendran (1998) en India, estimaron una disminución en el rendimiento del 15,9 al 36,6\% en el número y peso promedio de frutos de papaya, es decir, por cada aumento de nematodos en $5 \mathrm{~g}$ de raíz hallaron una pérdida de $0,35 \%$ en el rendimiento de la fruta $(0,811 \mathrm{~g}$ por árbol) debido a $M$. incognita. Además, determinaron que el nivel de agresividad de $M$. incognita fue un juvenil por $g$ de suelo, suficiente para reducir los parámetros de crecimiento de las plantas y para alterar la fisiología del fruto.

En Costa Rica, el género Meloidogyne spp. está asociado a una gran variedad de cultivos de importancia agrícola de hortalizas como brócoli, coliflor, culantro, chile, tomate, zanahoria, raíces y tubérculos como papa, ñampí, ñame, yuca, frutales entre ellos mango, durazno, papaya, guanábana y otros (Esquivel y Peraza 2010). No existe información que relacione el daño de las plantas con la presencia de esta plaga, o la caracterización a nivel de especie. La correcta identificación de este nematodo facilitaría la implementación de técnicas de combate, como el uso de cultivares resistentes y la ejecución de medidas cuarentenarias (Vovlas et al. 2005). Los procedimientos de identificación a nivel de género o especie basados en la observación de caracteres morfológicos y morfométricos son lentos, requieren de tiempo, un amplio conocimiento sobre taxonomía de nematodos y en algunos casos no son concluyentes (Taylor y Sasser 1978, Brito et al. 2004).

Actualmente, los procedimientos tradicionales de identificación se combinan con técnicas moleculares de análisis del genoma que permiten una caracterización más precisa. Dentro de los análisis moleculares se utiliza la reacción en cadena de la polimerasa (PCR por sus siglas en inglés) (Mullis et al. 1986), la técnica RFLP (Polimorfismo en la Longitud de los 
Fragmentos de Restricción) y la secuenciación con las cuales se obtiene un patrón de digestión único para cada especie. Luego mediante el uso de primers/indicadores, amplifican una región conservada y polimórfica en su longitud que son de diferente tamaño para cada especie (Montero et al. 2007).

En la presente investigación, se integraron métodos morfológicos y moleculares para determinar la especie de Meloidogyne responsable de producir agallas en el sistema radical de plantas de papaya, provenientes de una plantación comercial en Pococí, Limón, Costa Rica.

\section{MATERIALES Y MÉTODOS}

Sitio de muestreo. Se llevó a cabo en abril de 2015 en una parcela de aproximadamente 0,5 ha con una densidad de siembra de 900 plantas.ha ${ }^{-1}$. La parcela pertenece al Instituto Nacional de Tecnología Agropecuaria (INTA) en Pococí, Guápiles, Limón $\left(10^{\circ} 15^{\prime} 28.56^{\prime \prime} \mathrm{N}\right.$ y $\left.83^{\circ} 46^{\prime} 14.62^{\prime \prime} \mathrm{O}\right)$, se encuentra a una altura de $150 \mathrm{msnm}$ con una precipitación anual de 3500 a $5000 \mathrm{~mm}$ anuales y una temperatura promedio de 17 a $23^{\circ} \mathrm{C}$, lo que la ubica en bosque muy húmedo tropical (bmh-T) (Holdridge 1982).

Se tomaron 20 submuestras de suelo de $100 \mathrm{~g}$ y diez submuestras de $5 \mathrm{~g}$ al azar, las cuales se llevaron al Laboratorio de Nematología de la Escuela de Ciencias Agrarias (ECA) de la Universidad Nacional para su análisis.

Extracción de nematodos e identificación morfométrica. Se extrajeron hembras, juveniles y masas de huevos de Meloidogyne sp. a partir de raíces con agallas por medio de una aguja de disección y un estereoscopio a $45 \mathrm{X}$. Luego, varias hembras se colocaron en portaobjetos para observar e identificar la especie de acuerdo con el método descrito por Franklin (1962). Se comparó la morfología de los diseños perineales con descripciones e ilustraciones elaboradas por Esser et al. (1976), López y Dickson
(1977), Taylor y Sasser (1978), Whitehead (1968). Un total de 25 juveniles y diez hembras se identificaron con base en sus características morfológicas mediante las claves taxonómicas de Luc et al. (1990) y Mai et al. (1964). Se midió en los juveniles, la longitud del cuerpo, ancho del cuerpo, ancho del cuerpo a nivel del ano, longitud del estilete, ancho de la región labial, desembocadura de la glándula faríngea, distancia de la cabeza hasta el poro excretor, longitud del esófago, longitud de la cola, porción de la región hialina. Asimismo, se tomaron otras medidas para relacionar la proporción de los juveniles con respecto al largo del nematodo versus ancho del cuerpo, longitud del esófago, longitud de la cola y finalmente, ancho del cuerpo a nivel del ano. En el caso de los machos únicamente se realizaron mediciones de la longitud del estilete y de la desembocadura de la glándula faríngea dorsal desde la base del estilete (DGO). Se tomaron imágenes de hembras, huevos y juveniles con una cámara digital integrada y adaptada a un microscopio con contraste de interferencia diferencial (DIC). Cada fotografía se editó con el programa Photoshop CS6®.

\section{Análisis molecular}

Extracción de ADN. Se utilizaron 10 juveniles que individualmente se transfirieron a un tubo de PCR de 0,2 $\mathrm{ml}$ con $47 \mu \mathrm{l}$ de Tris- $\mathrm{HCl} 0,2$ $\mathrm{M}(\mathrm{pH} 8,0)$ y $5 \mu \mathrm{l}$ de proteinasa $\mathrm{K}\left(20 \mathrm{mg}^{-\mathrm{ml}^{-1}}\right)$. Los tubos con los nematodos se colocaron en un baño maría ultrasónico (Bransonic 2510, Branson Ultrasonidos ${ }^{\mathrm{TM}}$ ) durante $10 \mathrm{~min}$ a $60^{\circ} \mathrm{C}$ y posteriormente se incubaron durante $30 \mathrm{~min}$ a $60^{\circ} \mathrm{C}$ en un termociclador termociclador. Después se mezclaron con ayuda de un agitador tipo vórtex, se incubaron a $-20^{\circ} \mathrm{C}$ durante $15 \mathrm{~min}$ y a $90^{\circ} \mathrm{C}$ durante $10 \mathrm{~min}$. Posteriormente, la mezcla se volvió a agitar y se repitió nuevamente el ciclo de congelación/descongelación anterior. Por último, las muestras se agitaron en el vórtex durante $30 \mathrm{~s}$ y se centrifugaron durante $2 \mathrm{~min}$ a $2000 \mathrm{rpm}$ (Solano-González et al. 2015). Las suspensiones con el ADN se almacenaron a $-20^{\circ} \mathrm{C}$ para su posterior uso en PCR. 
Amplificación del ADN mitocondrial y análisis RFLP. Por medio de PCR se amplificó la región entre la subunidad II del citocromo oxidasa (COII) y la subunidad grande (16S) del ADN mitocondrial (ADNmt) con los primers $\mathrm{C} 2 \mathrm{~F} 3$ (5'-GGTCAATGTTCAGAAATTTGTGG-3') y 1108 (5'-TACCTTTGACCAATCACGCT-3'-) (Powers y Harris 1993). Se prepararon reacciones de PCR en tubos de $0,2 \mathrm{~mL}$ con un volumen final de $25 \mu$ que contenían la siguiente mezcla de reacción: buffer de la Taq polimerasa $1 \mathrm{X}$, dNTPs $0,08 \mathrm{mM}, \mathrm{MgCl}_{2} 1,0 \mathrm{mM}$, imprimadores a 0,8 $\mu \mathrm{M}$ cada uno, $0,8 \mathrm{U}$ de Taq polimerasa y $15 \mu \mathrm{L}$ de ADN. La amplificación del ADN se llevó a cabo en un termociclador (Veriti 96-Well, Thermo Scientific $\left.{ }^{\circledR}\right)$ de 96 pozos bajo las siguientes condiciones de temperatura: una fase de desnaturalización inicial a $94^{\circ} \mathrm{C}$ durante $2 \mathrm{~min}$, seguida de 35 ciclos de 10 seg de desnaturalización a $94^{\circ} \mathrm{C}, 30$ seg de alineamiento a $48^{\circ} \mathrm{C}$ y 2 min de extensión a $68^{\circ} \mathrm{C}$ y una fase final de extensión a $72^{\circ} \mathrm{C}$ durante $2 \mathrm{~min}$.

Los productos de PCR se trataron posteriormente con las enzimas de restricción $A l u \mathrm{I}$ y DraI en forma independiente, según las indicaciones por la casa fabricante. Para ello se prepararon reacciones de $15 \mu \mathrm{L}(5 \mu \mathrm{L}$ de producto de PCR, $1 \mu \mathrm{L}$ de enzima, $1,5 \mu \mathrm{L}$ del buffer de reacción de la enzima a $1 \mathrm{X}, 7,5 \mu \mathrm{L}$ de agua ultrapura) y se incubaron durante $1 \mathrm{~h} \mathrm{a} 37^{\circ} \mathrm{C}$ en el termociclador.

Los fragmentos de PCR y RFLP se separaron por medio de electroforesis en geles de agarosa de 1,5 y $2 \%$ respectivamente, preparados con TBE 1X. Los geles se corrieron dentro de una cámara de electroforesis a $90 \mathrm{~V}$ durante $1 \mathrm{~h}$ y 30 min. Los fragmentos de ADN se visualizaron y se digitalizaron en un fotodocumentador con un transiluminador de luz UV después de teñir los geles con Gel Red a 3X.

\section{RESULTADOS Y DISCUSIÓN}

Las raíces recolectadas mostraron síntomas severos de agallamiento (Figura 1). Se extrajeron un total de $200 \mathrm{~J}_{2} / 100 \mathrm{cc}$ de suelo y $3952 \mathrm{~J}_{2} / 10 \mathrm{~g}$ en raíz de Meloidogyne javanica. En el campo no se observaron síntomas de clorosis, enanismo, escaso desarrollo vegetativo o poca producción lo que podría estar relacionado a un buen manejo de la plantación. De acuerdo con Rojas (2010), la salud general observada en una parcela o finca se relacionada a prácticas de manejo en el uso de fertilización y materia orgánica.
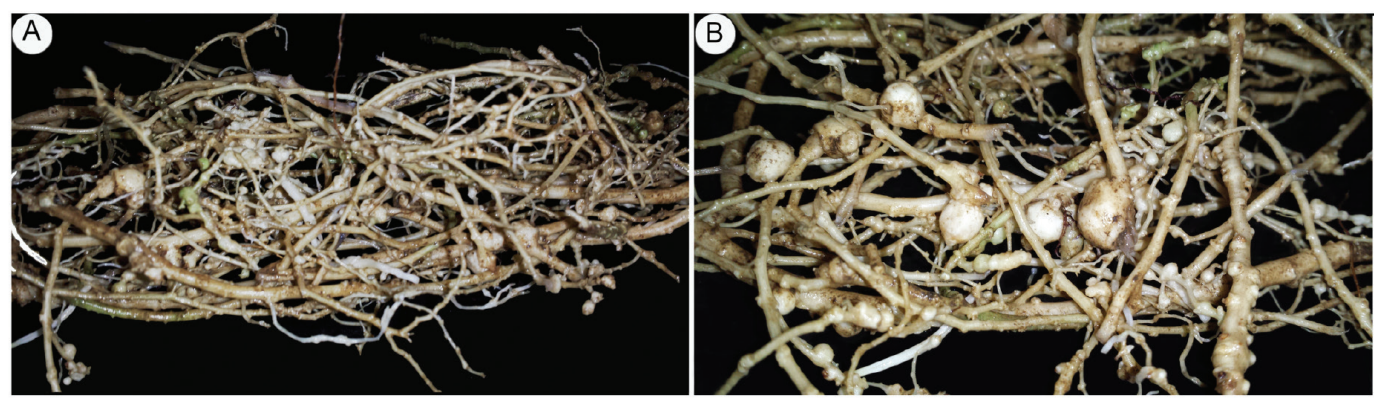

Figura 1. A y B. Agallamiento inducido por M. javanica en raíces de papaya (C. papaya L.). Cultivada en Pococí, Limón, Costa Rica. 2015.

Actualmente en Costa Rica no existen referencias acerca de límites de tolerancia y umbrales económicos; sin embargo, los resultados de estudio muestran altas densidades poblacionales principalmente en raíz que se presume podrían afectar la producción de este 
cultivo. En ocasiones se observaron en lotes o fincas, algunos árboles con poco crecimiento con respecto a los demás, también clorosis, marchitez y hasta una disminución en fructificación. Según Khan y Husain (1991), se debe considerar no solo las condiciones experimentales y ambientales, sino también la virulencia de la población de nematodos. En algunas ocasiones la infestación con otros patógenos puede formar un complejo plaga-hospedante difícil de controlar como es el caso de este nematodo que causa un daño severo a la raíz y posibilita la entrada de Phytophthora sp (Diaz 2002).
Identificación morfológica y morfométrica. El patrón perineal de las 25 hembras mostró un arco dorsal alto e incisiones laterales (estrías transversales) marcadas que separan las regiones dorsal y ventral y que a su vez se extienden a ambos lados del extremo de la cola y que son únicas para la especie $M$. javanica (Figura 2). Además, se observó que las crestas recorren todo el ancho del patrón, pero desaparecen gradualmente cerca del extremo de la cola. Las estrías son lisas o ligeramente onduladas y algunas pueden doblarse hacia los bordes vulvares (Figura 2). Estos resultados coinciden con los reportados por Chaful y De'Arc (1994) en Brasil, Espinosa et al. (2004), Jaraba et al. (2007) en Colombia y Cid del Prado et al. (2011) en México. 

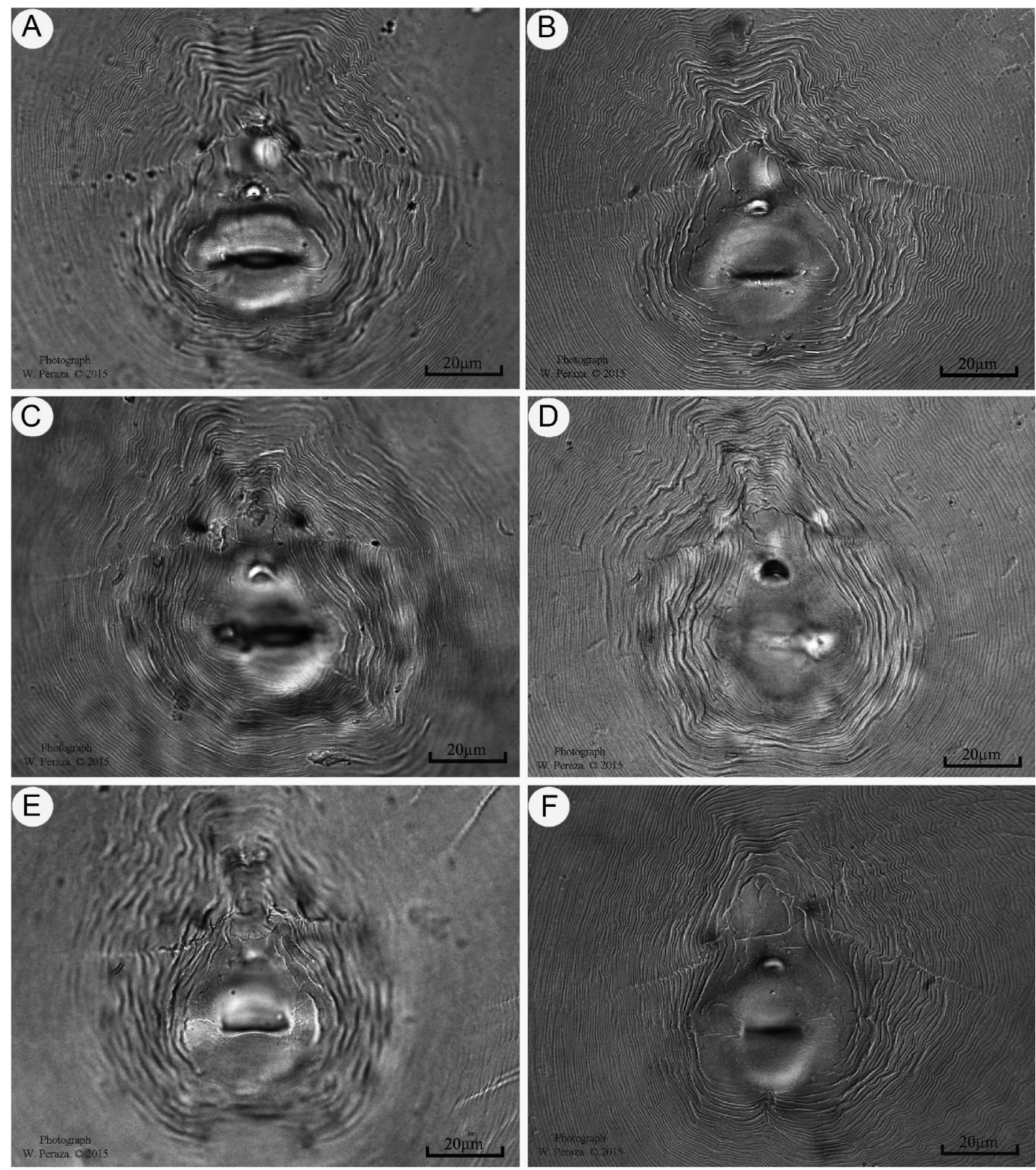

Figura 2. A-F. Fotomicrografías a escala $=20 \mu \mathrm{m}$ del patrón perineal de hembras de $M$. javanica provenientes de una plantación de papaya (C. papaya L.).

Cultivada en Pococí, Limón, Costa Rica. 2015. 
El patrón perineal es una característica valiosa y utilizada en la identificación de especies del género Meloidogyne (Chitwood 1949, Eisenback et al. 1980, Hirschmann 1985). No obstante, debido a la variabilidad intraespecífica y similitudes morfológicas dificulta en muchas ocasiones una correcta identificación (Pamjav et al. 1999). En el presente estudio, no hubo dificultad en la identificación de los diseños, ya que todos ellos presentaron características similares para la especie. En el caso M. arenaria, presenta un diseño perineal con un arco dorsal bajo, redondeado, pero a diferencia de $M$. javanica, sin líneas laterales evidentes marcadas por estrías cortas, irregulares y bifurcadas (Eisenback 1985).

Asimismo, el patrón perineal de $M$. incognita, presenta un arco dorsal alto y cuadrado sin líneas laterales y la presencia de bifurcaciones en las estrías a diferencia de M. javanica (Eisenback 1985). Sin embargo, es importante mencionar que en estudios realizados por Brito et al. 2004, observaron variaciones morfológicas en un patrón perineal para una especie en específico, las cuales podrían coincidir o ser similares para otra especie.

En la medición de las 10 hembras, se determinó que el largo fue de $608,0 \pm 42,1$ (547,7$643,2 \mu \mathrm{m})$, el ancho de 392,2 $\pm 17,2$ (355,3-432,8 $\mu \mathrm{m})$, la longitud del cuello de $219,4 \pm 10,8$ (194,2$254,7 \mu \mathrm{m})$. Con respecto al estilete, presentó una longitud de 16,0 $\pm 0,72(14,8-16,9 \mu \mathrm{m})$ mientras que la distancia del orificio de la glándula dorsal esofágica (DGO) fue de una longitud de 4,2 $\pm 0,16$ $(4,0-4,5)$ (Figura 3). En investigaciones realizadas, Jepson (1987) determinó que en promedio el largo de hembras de hembras de $M$. javanica fue de $672,5 \mu \mathrm{m}$ con un rango entre 545 a 800 $\mu m$, mientras que el ancho del cuerpo 422,5 con un rango entre 300 a $545 \mu \mathrm{m}$. Finalmente, el largo del estilete tuvo un promedio de $16 \mu \mathrm{m}$ con un rango entre 14 a $18 \mu \mathrm{m}$. Por su parte, en estudios taxonómicos realizados por Kaur et al. (2016) para esta misma especie, encontró qué, las hembras presentaban en promedio un largo de $654,5 \mu \mathrm{m}$ con un rango entre 519 a $790 \mu \mathrm{m}$; el ancho fue de $402 \mu m$ con un rango de 287 a $517 \mu \mathrm{m}$ y por último, la longitud del cuello con un promedio de $214,5 \mu \mathrm{m}$ y un rango entre 129 a $300 \mu \mathrm{m}$. En el caso del estilete un promedio de $16 \mu \mathrm{m}$ con un rango entre 14 a $18 \mu m$ y el DGO un promedio de $3,8 \mu \mathrm{m}$ con un rango entre 2,9 a 4,8 $\mu \mathrm{m}$. Asimismo, Espinosa et al. (2004), determinaron los parámetros morfométricos de la longitud del estilete de $15,4 \mu \mathrm{m} \pm 0,7 \mu \mathrm{m}$ (14$16 \mu \mathrm{m})$ y del DGO $3,2 \mu \mathrm{m} \pm 0,6 \mu \mathrm{m}(2-4 \mu \mathrm{m})$ los cuales junto con las otras investigaciones se encuentran dentro del rango para la descripción original de la especie y coinciden con la población de M. javanica de este estudio.
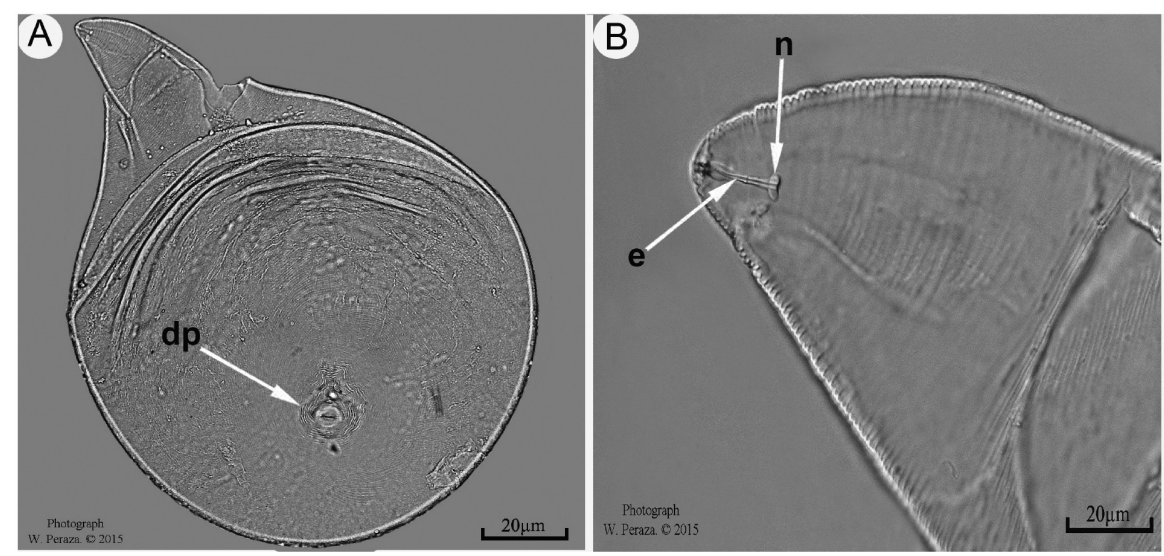

Figura 3. Fotomicrografías a escala $=20 \mu \mathrm{m}$ que permiten observar hembras de $M$. javanica. A. Hembra completa que muestra el patrón del diseño perineal (dp). B. Parte anterior de la hembra en la posición del poro excretor (pe), estilete (e) y nódulos (n). Plantación de papaya (C. papaya L.). Pococí, Limón, Costa Rica. 2015. 
Con respecto a los machos, estos presentaron en su parte anterior, un disco labial grande y plano, con labios medios fusionados en una región cefálica alta. También al medir tanto el estilete como el DGO, presentaron rangos de longitud de entre 15,3 a $16,8 \mu \mathrm{m}$ y de 2,2 a $3,8 \mu \mathrm{m}$ respectivamente; ambos dentro del rango para la especie $M$. javanica reportado por Eisenback (1985) y Espinosa et al. (2004).

El análisis morfométrico de 25 juveniles del segundo estadio $\left(\mathrm{J}_{2}\right)$ (Tabla 1, Figura 4) mostró que el valor promedio de la longitud del cuerpo de los estadios juveniles medidos fue de $419,2 \mu \mathrm{m}$, con un ancho del cuerpo de 13,1 (12,513,7) $\mu \mathrm{m}$. La longitud del estilete fue de 11,8 $\mu \mathrm{m}$, mientras que el ancho del cuerpo a nivel del ano fue de 9,8 $\mu \mathrm{m}$ y el ancho de la región labial de $4,7 \mu \mathrm{m}$. La distancia de la glándula esofágica dorsal desde la base del estilete fue de $3,5 \mu \mathrm{m}$. Finalmente, longitud de la cola fue de 49,3 $\mu \mathrm{m}$ y la porción hialina de $12,1 \mu \mathrm{m}$.

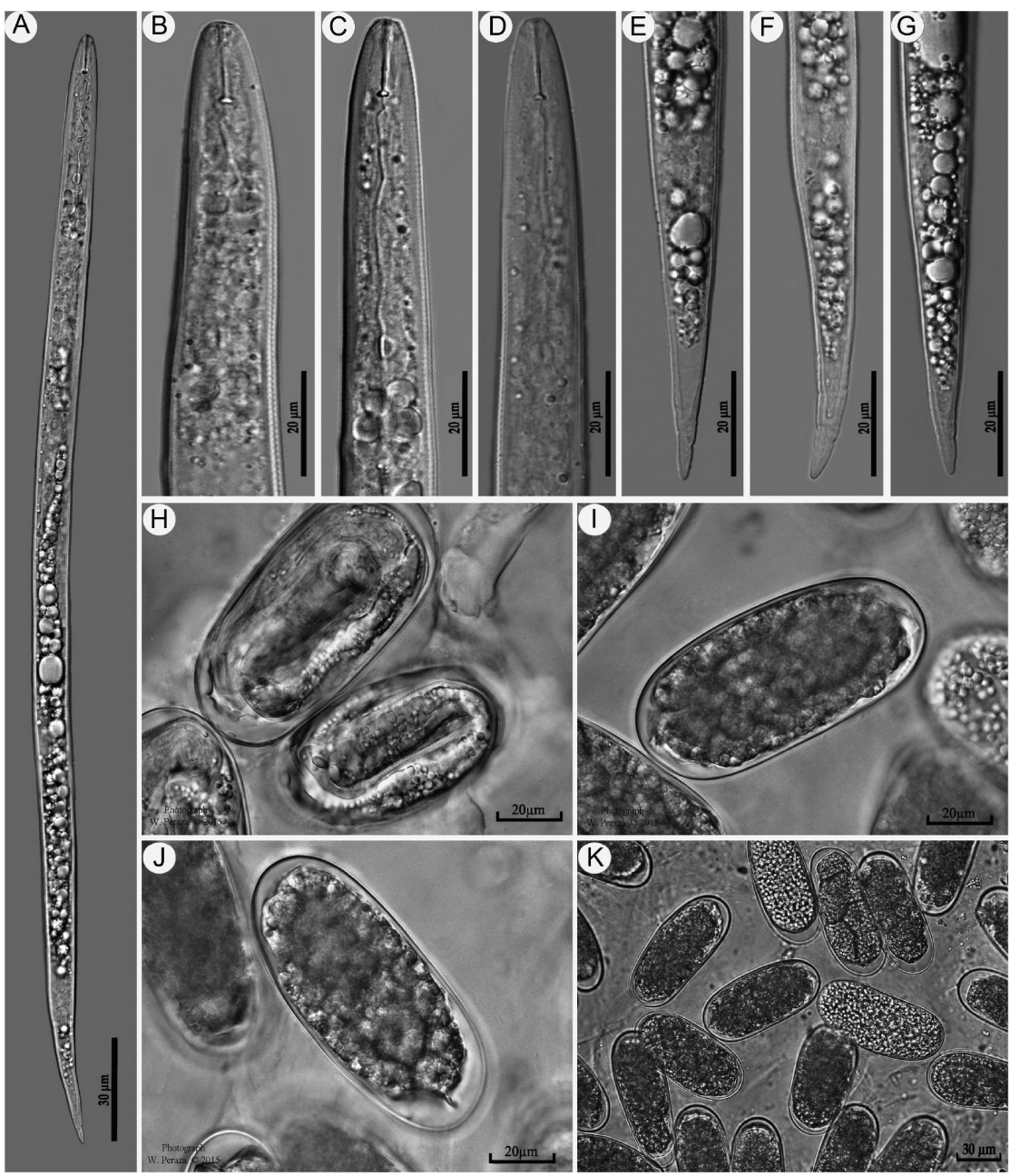

Figura 4. Fotomicrografías de segundos estados juveniles y huevos de M. javanica de una plantación de papaya (C. papaya L.). A. Segundo estado juvenil $\left(\mathrm{J}_{2}\right)$. B, C y D. Región anterior de J2 en la posición del estilete (e), nódulos (n), glándula dorsal esofágica (gde), y metacorpus (m). E, F y G. Región posterior de $\mathrm{J}_{2}$ donde se muestra el ano (a) y la región hialina de la cola (rh). H, I, J (Huevos (h) de hembras de M. javanica) y K. Escala: A=30 $\mu \mathrm{m}, \mathrm{B}-\mathrm{J}=20 \mu \mathrm{m}, \mathrm{K}=30 \mu \mathrm{m}$. Cultivo en Pococí, Limón, Costa Rica. 2015. 
Todos los caracteres morfológicos de importancia diagnóstica (Tabla 1) y referentes a la población de $M$. javanica en estudio, presentaron valores que se encuentran dentro del rango para dicha especie (Whitehead 1968, Jepson 1987, Kaur et al. 2016). Asimismo, al comparar las mediciones de la población de M. javanica también presentó similitud con estudios llevados a cabo por Williams (1972), Özarslandan y Elekçioğlu (2010) y Öztürk et al. (2020). No obstante, un estudio realizado por
Rusinque et al. (2018), con una población de $M$. javanica de Portugal, mostró similitudes con la población en estudio en el largo del nematodo y el DGO, no así en las medidas de la región hialina $(14,0[10,0-18,0]$ versus $12,1[11,0-13,9])$, largo del estile (55,3 [49,9-60,8] versus 49,3 $[45,8-55,5])$ y la cola $(55,3[49,9-60,8]$ versus $49,3[45,8-55,5])$, las cuales fueron inferiores en la población en estudio; sin embargo, estos valores se encuentran dentro del rango para la descripción de la especie.

Tabla 1. Comparación morfométrica de juveniles de segundo estadio $\left(\mathrm{J}_{2}\right)$ en una plantación de papaya (C. papaya L.). Pococí, Limón, Costa Rica, 2015.

\begin{tabular}{lcc}
\hline Medidas y relaciones $(\mu \mathrm{m})$ & $\begin{array}{l}\text { M. javanica }(\mathrm{n}=20) \\
\text { Papaya (presente estudio) }\end{array}$ & $\begin{array}{l}\text { M. javanica } \\
\text { (Jepson 1987) }\end{array}$ \\
\hline Longitud del cuerpo (L) & $\mathrm{a} 419,2 \pm 14,4(398,1-448,2)$ & $387-459$ \\
Ancho máximo del cuerpo (MBW) & $13,1 \pm 0,4(12,5-13,7)$ & $11-13,6^{*}$ \\
Ancho del cuerpo a nivel del ano (ABW) & $9,8 \pm 0,5(9,3-10,7)$ & - \\
Longitud del estilete (E) & $11,8 \pm 1,2(10,4-14,6)$ & $9,4-11,4$ \\
Ancho de región labial (LRW) & $4,7 \pm 0,1(4,5-5,0)$ & - \\
Desembocadura de la glándula faríngea dorsal desde la base del estilete (DGO) & $3,5 \pm 0,3(3,2-4,0)$ & $2-3,2^{*}$ \\
Distancia desde la cabeza hasta el poro excretor & $84,0 \pm 3,6(76,4-89,1)$ & $62,9-85,0^{*}$ \\
Longitud del esófago (Le) & $115,3 \pm 1,3(113,8-118,3)$ & - \\
Longitud de la cola (Lc) & $49,3 \pm 3,3(45,8-55,5)$ & $46,8-59,8^{*}$ \\
Porción hialina & $12,1 \pm 0,9(11,0-13,9)$ & $9-18$ \\
a (L/MBW) & $30,7 \pm 1,6(27,8-33,0)$ & $27,1-35,9^{* *}$ \\
b (L/Le) & $3,6 \pm 0,1(3,4-3,9)$ & - \\
c (L/Lc) & $8,3 \pm 0,3(7,9-9,2)$ & $7,3-8,1 * *$ \\
c' (Lc/ABW) & $5,0 \pm 0,4(4,4-5,6)$ & - \\
\hline
\end{tabular}

aPromedio \pm desviación estándar (rango); $\mathrm{n}=$ número de especímenes analizados.

*Medidas tomadas de Kaur et al. (2016).

**Medidas tomadas de Whithead (1968).

De acuerdo con Hirschmann (1985), las medidas entre especies son en muchas ocasiones estrechas, por lo que es común encontrar que algunas de ellas se superponen entre sí. En el caso de la longitud de la cola, es una de las características más útiles porque varía considerablemente entre especies y tiene poca variación intraespecífica lo que ayuda a distinguir con mayor facilidad entre ellas (Karssen y Moens 2006).

Análisis molecular. La amplificación del ADN de la región mitocondrial COII/16S a partir de los imprimadores $\mathrm{C}_{2} \mathrm{~F}_{3} / 1108$ generó un fragmento de aproximadamente $1,7 \mathrm{~kb}$ para cada uno de los individuos analizados (Figura 5). 
El peso molecular de $1,7 \mathrm{~kb}$ obtenido para $M$. javanica, concuerda con el reportado en investigaciones previas por Powers y Harris (1993), Williamson et al. (1994); Orui (1998), Han et al. (2004); Brito et al. (2004), Flores (2008) y Oh et al. (2009). No obstante, en estudios realizados por Powers y Harris (1993), Orui, (1998), Oh et al. (2009) para M. incognita y Orui (1998), Oh et al. (2009) para M. arenaria también reportaron un peso molecular de $1,7 \mathrm{~kb}$ para las especies mencionadas. Sin embargo, en este estudio al utilizar diferentes enzimas de restricción se pudo discriminar entre las 3 especies (M. arenaria, M. incognita y M. javanica).

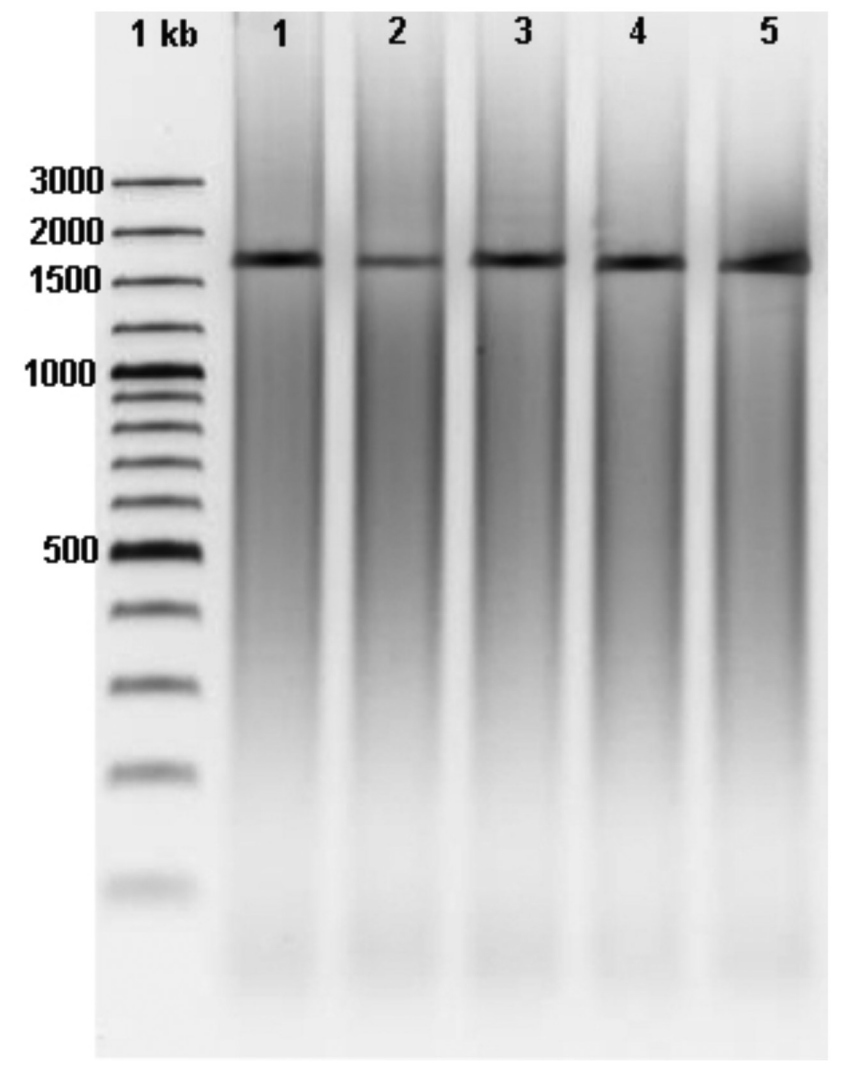

Figura 5. Electroforesis en gel de agarosa al $1 \%$ de los productos de la amplificación (PCR) de la región de mitocondrial COII/16S con los imprimadores C2F3/1108 (Powers y Harris 1993). Marcadores de peso molecular de $1 \mathrm{~kb}$. Carriles 1-5: juveniles de $M$. javanica.

Pococí, Limón, Costa Rica. 2015.

Al cortar el fragmento de $1,7 \mathrm{~kb}$ obtenido para $M$. javanica generó con la endonucleasa Alu I tres fragmentos, uno de 250, 460 y 1000 pb (Figura 6, carriles 2 y 6) mientras que con la enzima DraI cuatro, uno de 85, 105, 150, 600 y 600 pb (Figura 6, carriles 3 y 7) (Orui 1998).
En el caso de la endonucleasa $\operatorname{Hinf} \mathrm{I}$, no hubo corte de la enzima, es decir, generó un fragmento similar al del producto no cortado de $1,7 \mathrm{~kb}$ (Figura 6, carriles 4 y 8) y coincidió con resultados obtenidos por Orui (1998), Flores (2008) y Oh et al. (2009). 


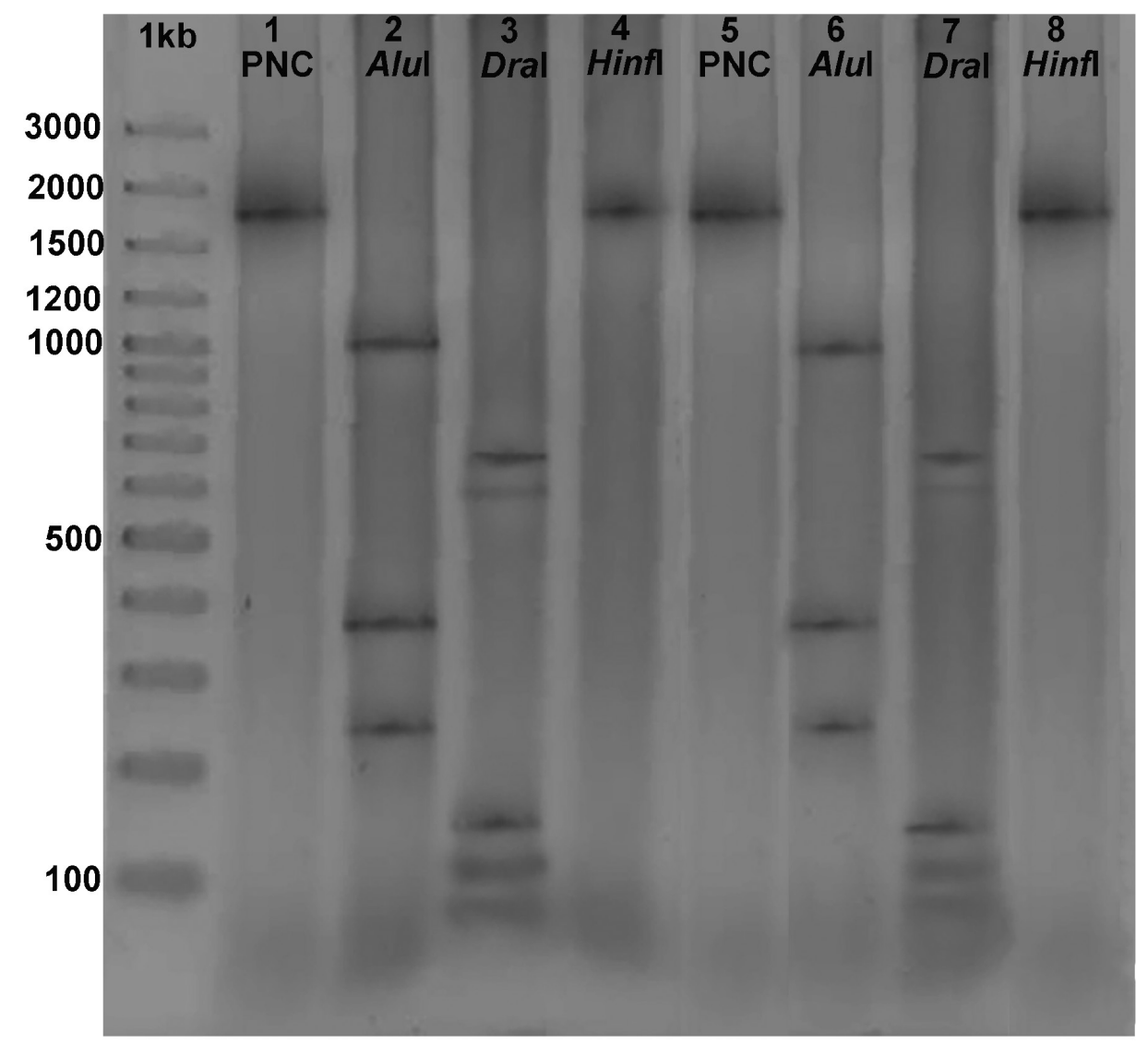

Figura 6. Patrones generados con las enzimas de restricción AluI, DraI y Hinf I mediante electroforesis en un gel de agarosa al 1,5\%. Carriles 1 y 5: Productos de PCR sin cortar con enzimas de restricción; Carriles 2 y 6: fragmentos generados con la enzima AluI; Carriles 3 y 7: fragmentos generados con la enzima DraI, Carriles 4 y 8: fragmentos generados con la enzima Hinf I. Marcador de peso molecular $1 \mathrm{~kb}$.

Pococí, Limón, Costa Rica. 2015.

Sin embargo, estudios de Powers y Harris (1993), Flores (2008), reportaron un producto de PCR para $M$. javanica tratado con la enzima de restricción $A l u \mathrm{I}$ que generó 3 fragmentos, uno de 150, 400 y 1000 pb. Asimismo, al comparar los fragmentos obtenidos con esta misma enzima para la especie $M$. incognita, investigaciones realizadas por Powers y Harris (1993), Flores (2008), indicaron la presencia de 3 fragmentos cuyo peso molecular fue de 230, 400 y $900 \mathrm{pb}$. Por su parte, Orui (1998) obtuvo fragmentos con pesos moleculares de 150, 250, 460 y 820 pb para esta misma especie lo que afirma la presencia de fragmentos diferentes.

En el caso de la enzima $\operatorname{Hinf} \mathrm{I}$ existen también el reporte de diferentes fragmentos. Por ejemplo, Orui (1998), Williamson et al. (1994) y Oh et al. (2009) reportaron para $M$. incognita 2 fragmentos, uno de 400 y otro de $1300 \mathrm{~kb}$. Asimismo, Powers y Harris (1993) determinó 3 fragmentos, uno de 300, 400 y 100 pb para esta misma especie con esta enzima.

De acuerdo con Peraza et al. (2013) aunque los juveniles de la población en estudio 
presentaron una morfología y taxonomía similar a poblaciones de esta especie en otras latitudes, las variaciones en el tamaño de los fragmentos que se generan con las enzimas de restricción pueden estar ligadas a variantes genéticas o polimorfismos dentro de una misma especie o población que se puede deber a mutaciones en el sitio de corte de las enzimas. Adicionalmente indica que otra razón por la cual existen distintos tamaños se podría obedecer a diferencias en el tiempo de corrida que hacen la visualización o ausencia de las diferentes bandas en un mismo gel.

Es importante aumentar el conocimiento e identificación de las principales especies de nematodos asociados a cultivos de importancia agrícola, ya que de esta manera no solo se podrá conocer su distribución y propagación, sino que también se logrará un diagnóstico preciso de cuáles especies podrían generar algún daño a un cultivo en particular. Además, al identificar y conocer una determinada especie, se pueden implementar algunas estrategias de combate, como la rotación de cultivos, el uso de cultivares resistentes y el establecimiento de regulaciones cuarentenarias con respecto al traslado de material vegetal y suelo de un sitio a otro para evitar la diseminación.

Para la correcta identificación de nematodos es necesario el uso de diferentes técnicas. Gracias a la utilización de algunas de ellas, se logró la caracterización de $M$. javanica asociada a una plantación de papaya.

\section{AGRADECIMIENTOS}

El autor desea expresar su agradecimiento al M.Sc. Antonio Bogantes Arias del Instituto de Innovación y Transferencia de Tecnología Agropecuaria (INTA) en Pococí, cantón de la provincia de Limón por su colaboración para la recolecta de las muestras de suelo y raíz.

\section{LITERATURA CITADA}

Bogantes, AA; Mora, EN; Umaña, GR; Loría, QCL. 2011. Guía para la producción de la papaya en Costa Rica.
Consultado 19 nov. 2016. Disponible en http//:www. mag.go.cr/bibliotecavirtual/a00321.pdf

Brito, J; Powers, TO; Mullin, PG; Inserra RN; Dickson, DW. 2004. Morphological and molecular characterization of Meloidogyne mayaguensis isolates from Florida. Journal of Nematology 36:232-240.

Castillo, P; Gómez-Barcina, A. 1993. Plant-parasitic nematodes associated with tropical and subtropical crops in southern Spain. Nematologia mediterranea 21:45-47.

Chaful, S; De' Arc, R. 1994. Mamão: Doenças causadas por fungos e nematoides en mamoerio. Informe Agropecuario 12(134):40-43.

Chitwood, BG. 1949. root-know nematodes, part I. A revision of the genus Meloidogyne Goeldi, 1887. Proceedings of the Helminthological society of Washington 16:90-104.

Cid del Prado, VI; Hernández, JA; Tovar, SA. 2011. Distribución de especies y razas de Meloidogyne en México. México. Revista Mexicana de Fitopatología 1(19):32-39.

Cohn, E; Duncan, L. 1990. Nematode parasites of subtropical and tropical fruit trees. In Luc, M; Sikora, RA; Bridge, J (eds.). Plant Parasitic Nematodes in Subtropical and Tropical Agriculture. Wallingford, U.K., C.A.B International. p. 347-362.

De La Cruz Medina, JG; Vela-Gutiérrez, G; García, HS 2003. Papaya Post-harvest Operations. Veracruz, México, FAO. 70 p.

Diaz, JJA. 2002. Manual para el cultivo de la papaya hawaiana. Guácimo, Costa Rica, EARTH. 108 p.

Eisenback, JD. 1985. Detailed morphology and anatomy of second-stage juveniles, males, and females of the genus Meloidogyne (root-knot nematodes). In Sasser, JN; Carter, CC (eds.). An Advanced Teatise on Meloidogyne. Volume I. Biology and Control. Raleigh, North Carolina. USA, A Cooperative Publication of the Department of Plant Pathology and the United States Agency for International Development, North Carolina State University Graphics. 477 p.

Eisenback, JD; Hirschmann, H; Triantaphy-Llou, AC. 1980. Morphological comparison of Meloidogyne female head structures, perineal patterns, and stylets. Journal of Nematology 12(4):300-313.

Espinosa, MR; Fuentes, KC; Jaraba, JD; Lozano, ZE. 2004. Nematodos asociados al cultivo de la papaya (Carica papaya L.) en Córdoba. Colombia. Temas agrarios 9:(1)13-20.

Esquivel, A; Peraza, W. 2010. Nematodos fitoparásitos asociados a cultivos agrícolas de Costa Rica. Heredia, Costa Rica. Consultado 03 jul. 2019. Disponible en https://es.scribd.com//document/195399234/ Manual-Cultivos-Final

Esser, RP; Perry, VG; Taylor, AL. 1976. A diagnostic compendium of the genus Meloidogyne Nematoda: 
Heteroderidae. Proceedings of the Helminthological Society of Washington 43:138-150.

Flores, L. 2008. Identificación de especies de Meloidogyne descritas en Costa Rica con base en la variabilidad del ADN mitocondrial. Tesis M.Sc. Costa Rica, Universidad de Costa Rica. 60 p.

Franklin, MT. 1962. Preparation of posterior cuticular patterns of Meloidogyne spp. for identification. Nematologica 7:336-337.

Han, H; Cho, MR; Jeon, ChY; Lim, ChK; Jang, HL. 2004. PCR-RFLP identification of three major Meloidogyne species in Korea. Journal of AsiaPacific Entomology 7(2):171-175.

Hine, RB; Holtzmann, OV; Raabe, RD. 1965. Diseases of Papaya (Carica papaya L.) in Hawaii. Bulletin $\mathrm{N}^{\circ}$. 136. Honolulu, Hawaii, Hawaii Agricultural Experiment Station, University of Hawaii. 28 p.

Hirschmann, H. 1985. The genus Meloidogyne and morphological characters differentiating its species. In Sasser, JN; Carter, CC (eds.). An Advanced Treatise on Meloidogyne. Volume 1, Biology and Control. Raleigh, North Carolina, North Carolina State University Graphics. p. 79-93.

Holdridge, L. 1982. Ecología basada en zona de vida. San José, CRC, Instituto Interamericano de Cooperación para la Agricultura. 216 p.

Hueso, JJ; Salinas, I; Pinillos, V; Cuevas, J. 2017. El cultivo de la papaya en el Sureste de España. Consultado 11 Jun. 2018. Disponible en https://www.interempresas. net/Horticola/Articulos/196398-El-cultivo-de-lapapaya-en-el-Sureste-de-Espana.html

INEC (Instituto Nacional de Estadística y Censos de Costa Rica). 2014. VI Censo Nacional Agropecuario, 2014. Costa Rica. s.p.

Inserra, RN; Cartia, G. 1976. Meloidogyne javanica su papaya in Silicia. Nematologia mediterranea 5:137-139.

Jaraba, JD; Lozano, Z; Espinosa, M. 2007. Nematodos agalladores asociados al cultivo de la papaya (Carica papaya L.) en el departamento de Córdoba, Colombia. Colombia. Agronomía Colombiana 1(25):124-130.

Jepson, SB. 1987. Identification of root-knot nematode (Meloidogyne species). Wallingford, UK, CAB International. $265 \mathrm{p}$.

Karssen, G; Moens, M. 2006. Root-knot nematodes. In Perry, RN; Moens, M (eds.). Plant Nematology. Wallingford, UK, CABI Publishing. p. 59-90.

Kaur, SS; Kang, S; Dhillon, NK; Sharma, A. 2016. Detection and characterization of Meloidogyne species associated with pepper in Indian Punjab. Nematropica 46:209-220.

Khan, A; Sayed, M; Shahid, S. 2007. Nematodes associated with papaya in Sindh, Pakistan. Sarhad Journal of Agriculture 23(1):145-148.

Khan, A; Sayed, M; Shaukat, SS; Handoo, ZA. 2008. Efficacy of four plant extracts on nematodes associated with papaya in Sindh, Pakistan. Nematología Mediterranea 36:93-98.

Khan, TA; Husain, SI. 1991. Effect of age of papaya seedlings on the development of disease complex caused by Meloidogyne incognita and Fusarium solani. Nematologia Mediterranea 19:327-329.

Koenning, SR; Overstreet, C; Noling, JW; Donald, PA; Becker, JO, Fortnum, PA. 1999. Survey of crop losses in response to phytoparasitic nematodes in the United States for 1994. Journal of Nematology 31:587-618.

Lamberti, F; Ekanayake, HMRK; Sasanelli, N. 1993. Effect of some plant parasitic nematodes on the growth of selected crops in Sri Lanka. Nematologia Mediterranea 10:225-230

Lamberti, F; Ekanayake, HMRK; Zacheo, F. 1980. Effect of two Meloidogyne species on the growth of papaw seedlings. Indian Journal of Nematology 10:225-230

López, R; Dickson, DW. 1977. Morfometría y respuesta de hospedantes diferenciales a tres poblaciones de Meloidogyne incognita y una de Meloidogyne javanica. Agronomía Costarricense 1(2):119-127.

Luc, M; Sikora, RA; Bridge, J. 1990. Plant-parasitic nematodes in subtropical and tropical agriculture. 2 nd. London, England, CAB International. 890 p.

Luc, M; Sikora, RA, Bridge, J. 2005. Plant parasitic nematodes in subtropical and tropical agriculture. 2 nd. Wallingford, UK, CAB International. 877 p.

Mai, WF; Lyon, HH; Kruk, TH. 1964. Pictorial key to genera of plant parasitic nematodes. 5 ed. New York, USA, Department of plant pathology, New York state College of Agriculture. $54 \mathrm{p}$.

McSorley, R. 1983. Population buildup and effects of the reniform nematode of papaya in Southern Florida. Fla. State Hort. Soc. 69:198-200.

McSorley, R. 1992. Nematological problems in tropical and subtropical fruit tree crops. Nematropica 22:103-116

Montero, Z; García, C; Salazar, L; Valverde, R; GómezAlpízar, L. 2007. Detección de Meloidogyne incognita en tubérculos de papa en Costa Rica. Agronomía Costarricense 31(1):77-84.

Mullis, K; Faloona, F; Scharf, S; Saiki, R; Horn, G; Erlich, H. 1986. Specific enzymatic amplification of DNA in vitro: the polymerase chain reaction. Cold Spring Harbor Symposium in Quantitative Biology 51:263-273.

Oh, Hyung Keun; Bae, Chang-Hwan; KIM, Man Il; Oh, Seung-Han; Han, Yeon-Soo; Lee, Hyang Burm; Kim, Iksoo. 2009. The Plant Pathology Journal 25:247-255. DOI: https://doi.org/10.5423/ PPJ.2009.25.3.247.

Orui, Y. 1998. Identification of Japanese species of the genus Meloidogyne (Nematoda: Meloidogynidae) 
by PCR-RFLP analysis. Applied Entomology and Zoology 33:43-51.

Özarslandan, A; Elekçioğlu, HI. 2010. Türkiyee"nin farklı alanlarından alınan Kök-ur nematodu türlerinin (Meloidogyne spp.) (Nemata: Meloidogynidae) moleküler ve morfolojik tanılama ile belirlenmesi. Türkiye Entomoloji Dergisi 34:323-335.

Öztürk, L; Aslan, A; Sivri, N; Şin, B; Behmand, T; Avc1, GG; Elekcioglu, IH. 2020. Meloidogyne javanica Treub, 1885 (Chitwood, 1949) and some weed hosts in tomato (Solanum esculentum L.) fields in Tekirdağ, Turkey. Munis Entomology \& Zoology, 15(1):26-34.

Pamjav, H; Triga, D; Buzas, ZT; Vellai, A; Lucska, I; Adams, A; Reid, AP; Burnell, A; Griffin, C; Glazer, I; Klein, MG; Fodor, A. 1999. Novel application of PhastSystem polyacrylamide gel electrophoresis using restriction fragment length polymorphism internal transcribed spacer patterns of individuals for molecular identification of entomopathogenic nematodes. Electrophoresis 20:1266-1273.

Peraza-Padilla, W; Rosales-Flores, Johaner; EsquivelHernández, A; Molina-Bravo, R; Castillo-Castillo, P. 2013. Identificación morfológica, morfométrica y molecular de Meloidogyne incognita en higuera (Ficus carica L.) en costa rica. Agronomía Mesoamericana 24(2):337-346.

Powers, TO; Harris, TS. 1993. A polymerase chain reaction method for identification of five major Meloidogyne species. Journal of Nematology 25:1-6.

PROCOMER (Promotora de Comercio Exterior de Costa Rica). 2017. La producción de papayas mexicanas disminuirá en las próximas semanas. Consultado 20 jun. 2020. Disponible en https://www.procomer. com/alertas_comerciales

Ramakrishnan, S; Rajendran, G. 1998. Assessment of yiel loss due to Meloidogyne incognita in papaya under fiel conditions. Nematologia Mediterranea 26:229-230.

Rojas, M. 2010. Nematodos del café. Revista informativa. CICAFE, Heredia, Costa Rica. Consultado 07 abr. 2020. Disponible en http://www.icafe.cr/cicafe/ publicaciones/revista-informativa-icafe/

Rusinque, L; Inácio, ML; Mota, M; Nóbrega, F. 2018. Morphological, biochemical and molecular characterization of Meloidogyne javanica, from North Portugal, in tomato. Revista de Ciências Agrárias 41(1):193-198.

SAGARPA (Secretaría de Agricultura, Ganadería, Desarrollo Rural, Pesca y Alimentación). 2017. México, Planeación Agrícola Nacional 2017-2030. 16 p.

Solano-González, S; Esquivel-Hernández, A; MolinaBravo, R; Morera-Brenes, B. 2015. Identification of Meloidogyne species associated with upland ornamentals plants in Costa Rica. Agronomía Mesoamericana 26(2):247-256. DOI: https://doi. org/10.15517/am.v26i2.19280.

Talavera, RM. 2003. Manual De Nematología Agrícola. Introducción al análisis y al control nematológico para agricultores y técnicos de agrupaciones de defensa vegetal. Consultado 10 nov. 2018. Disponible en http://www.caib.es/sacmicrofront/archivopub. do?ctrl $=$ CNTSP722ZI4569\&id $=4569$

Taylor, AL; Sasser, JM. 1978. Biology, identification and control of root-knot nematodes (Meloidogyne species). Raleigh, North Carolina, USA, North Carolina State University Graphics. 111 p.

Valencia, SK; Duana, ÁD; Hernández, GTJ. 2017. Estudio del mercado de papaya mexicana: un análisis de su competitividad (2001-2015). Suma de negocios 8:(18):131-139.

Vovlas, N; Mifsud, D; Landa, BB; Castillo, P. 2005. Pathogenicity of the root-knot nematode Meloidogyne javanica on potato. Plant Pathology 54:657-664.

Whitehead, AG. 1968. Taxonomy of Meloidogyne (Nematodea: Heteroderidae) with descriptions of four new species. Transactions of the Zoological Society of London 31:263-401.

Williams, KJO. 1972. Meloidogyne javanica. Commonwealth Institute of Helminthology (CIH). Descriptions of Plant-Parasitic Nematodes Set 1, No. 3. Farnham Royal, UK, Commonwealth Agricultural Bureaux. s. p.

Williamson, VM; Caswell-Chen, EP; Wu, FF; Hanson, D. 1994. PCR for nematode dentification. In Lamberti, F; De Giorgi, C; Bird, DM (eds.). Advances in molecular plant Nematology. New York, USA, Plenum Press. p. 119-127. 
